\title{
Transparent Microstrip GPS Antenna for Cubesat Applications
}

\author{
Mostafa Mahmoud Rabie ${ }^{*}$, Hadia El-Henawy ${ }^{\dagger}$, Fatma El-Hefnawy ${ }^{\ddagger}$, Fawzy Ibrahim ${ }^{\S}$
}

\begin{abstract}
Due to the small Size of Cubesats and their limited surface area, solar cells are placed underneath the microstrip antenna for surface area optimization. However, microstrip patch antenna suffers opacity and would block the solar cells from the visible spectrum. Therefore a transparent antenna design is needed. In this paper, a Circularly Polarized (CP) transparent Global Positioning System (GPS) microstrip antenna is proposed and designed. The required antenna specifications are: Operating frequency, fr $=1.575 \mathrm{GHz}$, Bandwidth, BW $\geq 2.9 \%$, Antenna Gain, $\mathrm{G} \geq 5 \mathrm{dBi}$, Antenna efficiency, e $\geq 85 \%$, Percentage of Transparency, $\mathrm{PT} \geq 50 \%$ and Circularly polarized.
\end{abstract}

Keywords: Microstrip Antenna, Circular Polarization, Global Positioning System (GPS), Transparent Antenna, Cube satellites, Cubesats.

\section{Introduction}

Cubesat is a type of pico-satellite for space research that is made up of multiples of $10 \times 10 \times 10$ $\mathrm{cm}$ cubic units. Cubesat has a mass of no more than 1.33 kilograms per unit. Cubesat can stand alone, one unit. Also two, three or more units can be connected to each other [1].

Microstrip antennas are widely used nowadays in cubesat applications, as a replacement of the traditional antenna type, which is the mechanically-deployed whip monopole. The mechanical type of monopole antennas used in such applications suffers a lack of performance and reliability, so it makes the satellite prone to failure and yet a total abort for the satellite mission [2] [3].

Patch antennas are opaque so solar panels on the cubes will be blocked. Transparent patch antennas are introduced to solve the problem of opacity, and to allow solar energy to reach the panels. Lots of research efforts were made on antenna integration with solar cells, in order to achieve both good antenna performance and maximum solar cells capacity. An alternative approach for constructing transparent antennas is to apply transparent conductors (conductive films), such as Indium Tin Oxide (ITO) films, onto a transparent substrate. Also another method for fabricating transparent antennas is by creating them from a conductive mesh structure placed on transparent substrates [2] [4] [5].

Global Positioning System (GPS) is considered the most efficient positioning approach, where it consists of 31 satellites in six Medium Earth Orbits (MEO). It uses very strong encryption techniques and provides high position accuracy. Many transportation and terrestrial systems use GPS in order to obtain time and position information [6].

MIU, Egypt; mostafa.hanafy@ miuegypt.edu.eg

Ain Shams University, Egypt

Electronics Research Center, Cairo, Egypt

MIU, Egypt. 
The transparent microstrip antenna introduced in this project is designed for the cubesat placed in the near earth orbits to communicate with the GPS constellation placed in the Medium Earth Orbit (MEO orbit) in order to provide precise time and position information of the cubesat.

This paper is organized as follows: Transparent meshed microstrip concept, transparency control and transparency measurement is illustrated in Section 2. Substrate selection, initial design of circularly polarized rectangular GPS microstrip antenna is introduced and simulated in Section 3. The design of circularly polarized transparent meshed GPS microstrip antenna is designed, simulated and results are analyzed in Section 4. The conclusions are given in section 5 .

\section{Transparent Meshed Microstrip Antenna Concept}

\subsection{Structure}

In order to achieve transparency using normal non transparent conductor such as copper material is sectioned into a grid design. This sectioning can be done by removing small rectangles from the conductor leaving only the connecting lines with the desired line thickness and desired number of horizontal and vertical lines as shown in Fig.1. The number of horizontal and vertical lines forming the mesh structure as well as the line thickness can be controlled by the areas of the small rectangles removed from the patch and the ground material using the following equations:

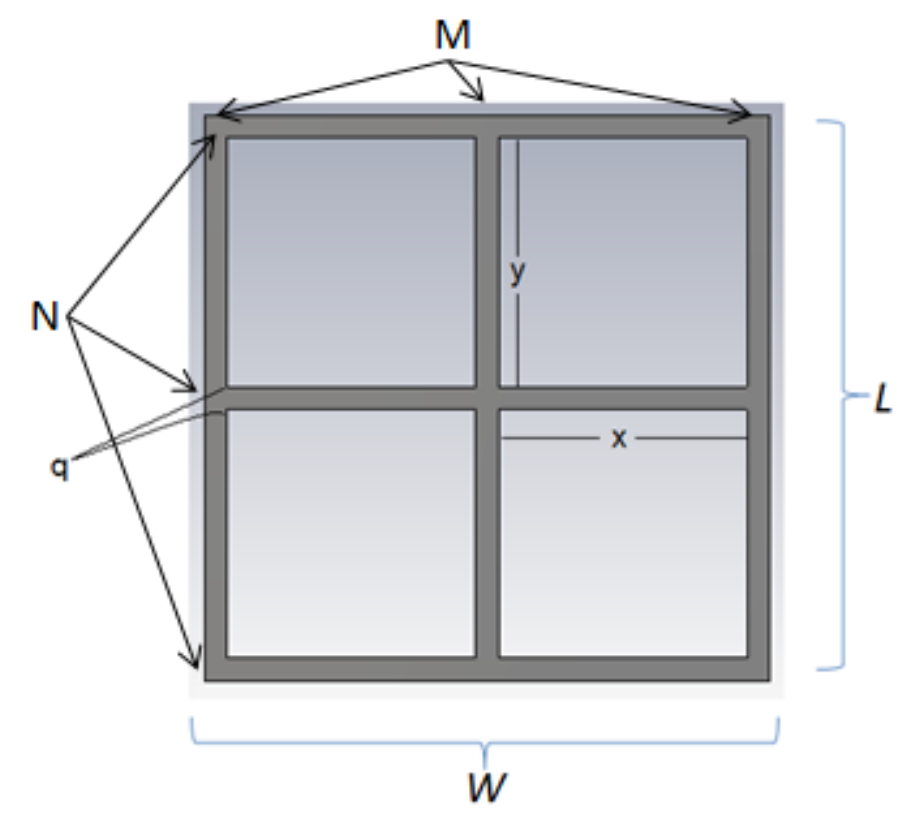

Fig.1 Patch material gridding

$$
\begin{aligned}
& x=\frac{W-M q}{M-1} \\
& y=\frac{L-N q}{N-1} \\
& A_{r e c}=x y
\end{aligned}
$$


where $\mathrm{x}$ is the width of the rectangle to be removed, $\mathrm{y}$ is the length of the rectangle to be removed, $\mathrm{A}_{\text {rec }}$ is the area of the rectangle to be removed. $\mathrm{L}$ is the Length of the patch, $\mathrm{W}$ is the width of the patch, $\mathrm{N}$ is the number of desired horizontal mesh lines parallel to the width of the patch. $\mathrm{M}$ is the number of desired vertical mesh lines normal to the width of the patch and $\mathrm{q}$ is the desired line width, as shown in Fig.1.

\subsection{Transparency Control and Measurement}

Transparency of the meshed Microstrip antenna can be controlled by selecting the number of horizontal lines $\mathrm{N}$, the number vertical lines $\mathrm{M}$ and the thickness of the single line $\mathrm{q}$. By reducing the number of horizontal and vertical lines as well as the thickness of the line, transparency increase but at the expense of efficiency.

The Percentage of Transparency (PT) of the meshed microstrip antenna can be determined as a ratio between the nonmetal areas (total removed rectangles) to metal area of the patch by the following equation:

$$
(P T)=\frac{(N-1)(M-1) \text { Arec }}{\text { Apatch }} \times 100 \%
$$

where Apatch is the area of the patch and is given by:

$$
\text { Apatch }=L p \times W p
$$

\section{Design of Rectangular Microstrip Antenna}

Our challenge is to design a transparent circularly polarized Global Positioning System (GPS) microstrip antenna, to achieve an acceptable system transparency.

\subsection{Substrate selection}

In order to allow solar energy and for the whole system to be transparent the selected substrate material should be transparent, otherwise gridding of the conductor (patch and ground) would be useless because the microstrip antenna will be opaque.

In this design the selected transparent substrate is Quartz. The main Quartz substrate specification are high working temperature, good thermal conductivity, high stability, anticorrosion, superior mechanical properties, stable dielectric constant $\varepsilon_{\mathrm{r}}=3.75$, low dielectric loss $\tan \delta=0.0004$, thickness $(\mathrm{h}=0.5 \mathrm{~mm}, 1 \mathrm{~mm}, 2 \mathrm{~mm}, 3 \mathrm{~mm}$ ), in addition to high optical transmission [11]. In this design, $\mathrm{h}$ is selected to be $(\mathrm{h}=3 \mathrm{~mm})$.

\subsection{Initial Design of Rectangular Microstrip Antenna}

Antenna specs are: Resonance frequency $\mathrm{f}_{\mathrm{r}}=1.575 \mathrm{GHz}$, Bandwidth, $\mathrm{BW} \geq 2.9 \%$, Antenna Gain, $\mathrm{G} \geq 5 \mathrm{dBi}$, Antenna efficiency, e $e_{0} \geq 85 \%$.

In order to calculate the dimensions of the patch length $\left(\mathrm{L}_{\mathrm{p}}\right)$ and width $\left(\mathrm{W}_{\mathrm{p}}\right)$ shown in Fig.2, the following design equations are used for starting the design of the microstrip antenna [13]. The effective dielectric constant, $\varepsilon_{\text {eff }}$ is given by:

$$
\varepsilon_{e f f}=\frac{\varepsilon r+1}{2}+\frac{\varepsilon r-1}{2}\left(1+12 \frac{h}{W}\right)^{\frac{-1}{2}}
$$


For an efficient radiator, a practical width that leads to good radiation efficiencies is given by the following equation:

$$
W_{p}=\frac{C}{2 f r}+\sqrt{\frac{2}{\varepsilon r+1}}=\frac{1}{2 f r \sqrt{\mu o \varepsilon o}} \sqrt{\frac{2}{\varepsilon r+1}}
$$

Because of the fringing effects, electrically the patch of the microstrip antenna looks greater than its physical dimensions. A very popular and practical approximate relation for the normalized extension of the length is:

$$
\frac{\Delta L}{h}=0.412 \frac{\left(\varepsilon_{\text {eff }}+0.3\right)\left(\frac{W_{p}}{h}+0.264\right)}{\left(\varepsilon_{\text {eff }}-0.258\right)\left(\frac{W_{p}}{h}+0.8\right)}
$$

Since the length of the patch has been extended by $\Delta \mathrm{L}$ on each side, the effective length of the patch now is:

$$
\begin{aligned}
L_{e f f} & =\frac{c}{2 f_{r} \sqrt{\varepsilon_{e f f}}} \\
L_{p} & =L_{e f f}-2 \Delta L
\end{aligned}
$$

Summary of the obtained results are listed in Table 1.

Table 1 Design equations results.

\begin{tabular}{|c|c|c|c|c|}
\hline$\varepsilon_{\text {eff }}$ & $W_{p}$ & $/ h \Delta L$ & $L_{\text {eff }}$ & $L_{p}$ \\
\hline 3.467 & $61.74 \mathrm{~mm}$ & 0.47151 & $51.1486 \mathrm{~mm}$ & $48.27 \mathrm{~mm}$ \\
\hline
\end{tabular}

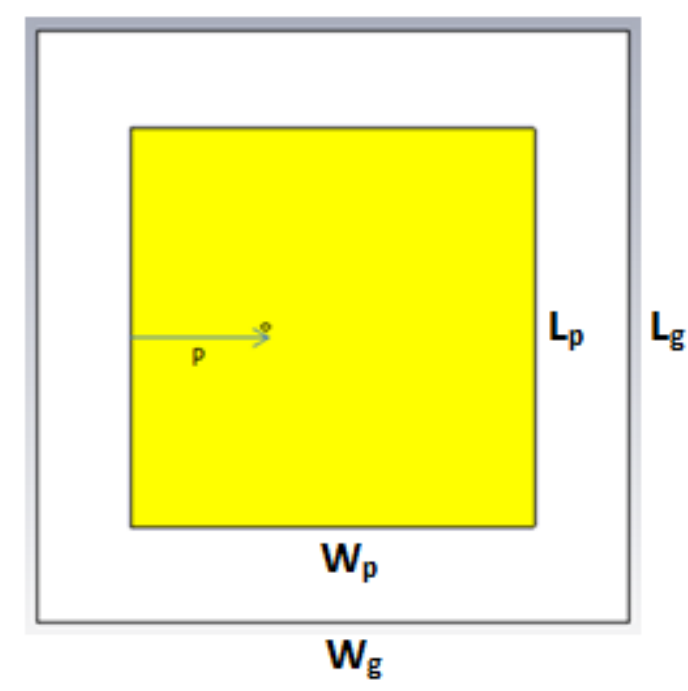

Fig.2 Microstrip antenna 


\subsection{Optimization of Rectangular Microstrip Antenna}

First design a non-meshed (solid) microstrip antenna with copper conductor and transparent substrate (quartz) is to test the performance of the designed antenna before gridding, also in order to compare between the performance of the solid and gridded antennas. The feeding point is placed at the center of the patch $(\mathrm{p}=\mathrm{Wp} / 2)$ as shown in Fig.2. The ground plane dimensions $\left(\mathrm{L}_{\mathrm{g}}\right.$ and $\left.\mathrm{W}_{\mathrm{g}}\right)$ are selected to be equal $\left(\mathrm{L}_{\mathrm{g}}=\mathrm{W}_{\mathrm{g}}\right)$ and approximately twice the patch length $\left(\mathrm{L}_{\mathrm{p}}\right)$.

After computation using the design equations [equation 6 - equation 9], the model of the antenna is simulated using finite element software (CST) and the antenna is designed to match the standard coaxial feeding method at $50 \mathrm{ohms}$.

Table 2 Initial design of the rectangular patch antenna.

\begin{tabular}{|c|c|c|c|c|}
\hline $\mathrm{L}_{\mathrm{p}}$ & $\mathrm{W}_{\mathrm{p}}$ & $\mathrm{L}_{\mathrm{g}}$ & $\mathrm{W}_{\mathrm{g}}$ & $\mathrm{P}$ \\
\hline $48.27 \mathrm{~mm}$ & $61.74 \mathrm{~mm}$ & $85 \mathrm{~mm}$ & $85 \mathrm{~mm}$ & $30.87 \mathrm{~mm}$ \\
\hline
\end{tabular}

The simulation result of the initial design is shown in Fig.3. It is clear from the $S_{11}$ parameter (return loss) of this initial design that the antenna is not radiating properly, the graph is above $-10 \mathrm{~dB}$ for the frequency band. This is due to the choice of the probe feeding location which affects the matching impedance at the required operation frequency. Accordingly, optimization to the location of the feeder is required.

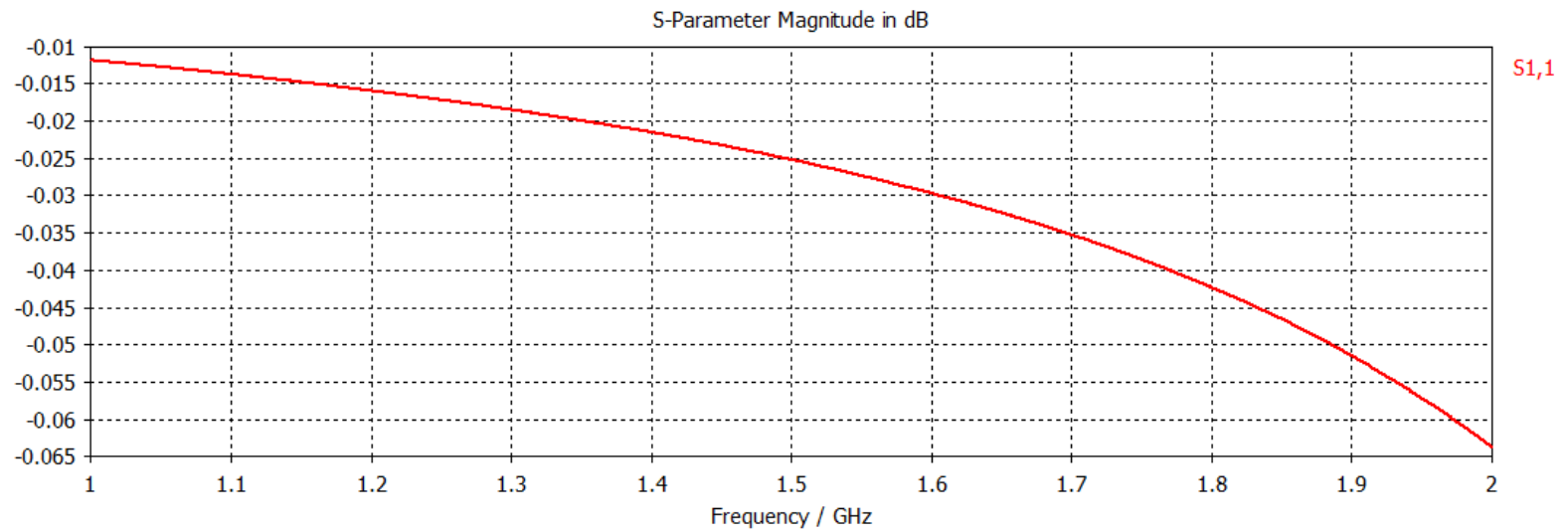

Fig.3 S11 parameter (Return Loss) centrally fed microstrip antenna

The next task is to determine the feed point $\mathrm{P}$ as shown in Fig.2, to obtain a good impedance match between the generator impedance and the input impedance of the patch element. It is observed that the change in feed location gives rise to a change in the input impedance and hence provides a simple method for impedance matching.

An expression for $\mathrm{P}$ is approximately given by the following equation [13]:

$$
P=\frac{W p}{2}\left(1-\frac{1}{\sqrt{\varepsilon e f f}}\right)
$$


After computing and optimizing the new feed location, optimization to the dimensions of the patch $\left(\mathrm{L}_{\mathrm{p}}, \mathrm{W}_{\mathrm{p}}\right)$ also took place to achieve the required resonance frequency. The optimized dimensions are given in Table 3.

Table 3 Design patch dimensions for matched rectangular microstrip antenna.

\begin{tabular}{|c|c|c|c|c|}
\hline $\mathrm{L}_{\mathrm{p}}$ & $\mathrm{W}_{\mathrm{p}}$ & $\mathrm{L}_{\mathrm{g}}$ & $\mathrm{W}_{\mathrm{g}}$ & $\mathrm{P}$ \\
\hline $48.3 \mathrm{~mm}$ & $48.9 \mathrm{~mm}$ & $85 \mathrm{~mm}$ & $85 \mathrm{~mm}$ & $14.5 \mathrm{~mm}$ \\
\hline
\end{tabular}

The S11 parameter of the antenna for the optimized feed location and dimensions is shown in Fig.6, where the antenna is matched with the carrier frequency. The gain is equal to $6.8 \mathrm{dBi}$ and the antenna efficiency is equal to $95.7 \%$.

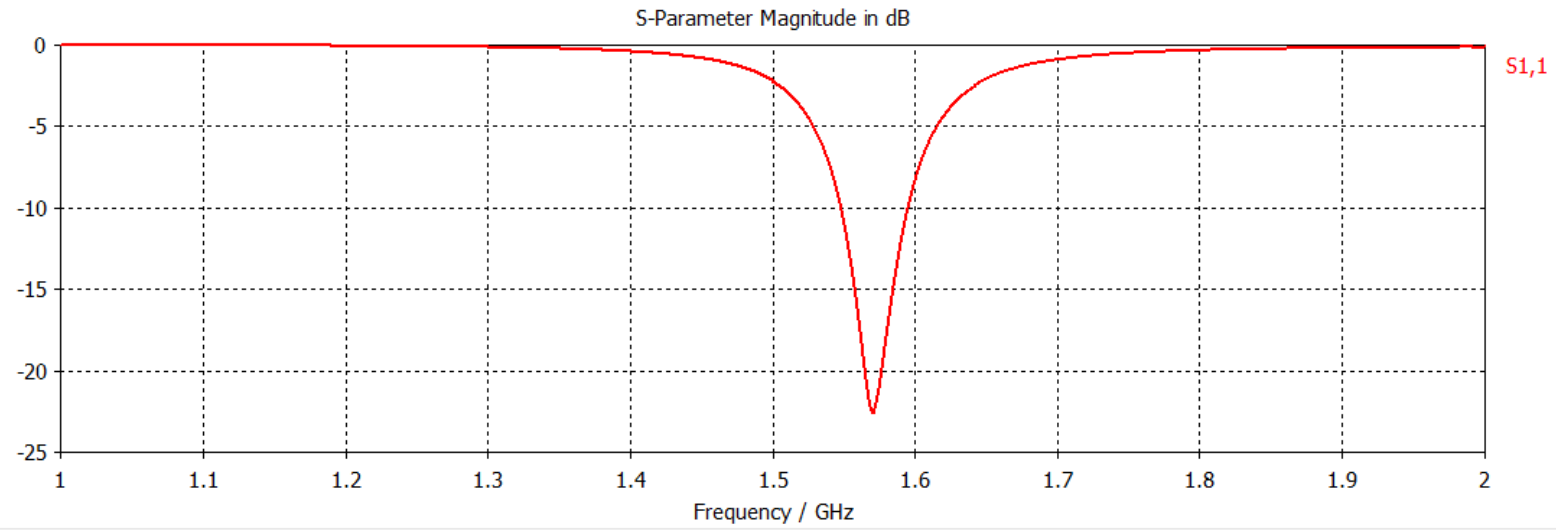

Fig.4 S11parameter (Return Loss) for the optimized feed location and dimensions microstrip antenna

The Axial Ratio is measured in a broadband direction about the operating frequency. It shows that the rectangular microstrip antenna is linearly polarized, where the Axial Ratio is equal to $40 \mathrm{~dB}$. In order to achieve circular polarization the Axial Ratio should be smaller than $3 \mathrm{db}$ [10] [13], so the design should be modified to achieve this requirement.

\subsection{Circular Polarization}

Many attempts were held before to design a circularly polarized microstrip GPS antenna. Pentagonal shaped microstrip antenna was one of the attempts printed on R04003C substrate [7]. Another circularly polarized GPS antenna design was the square microstrip antenna with T-shaped elements for vehicle applications [8]. Circular polarization was also achieved for the GPS microstrip antenna with one truncated corner on RT-Duroid substrate [9]. A dual band stacked microstrip GPS antenna with two patch layers, one of them is triangularly truncated at the edges and the other patch is rectangular truncated to achieve circular polarization [10]. The edges of the patch are isosceles triangularly truncated with dxd and the probe feeding point is located $\mathrm{P}$ distance from the left side of the patch [12] as shown in Fig.5, in order to achieve circular polarization.

The appropriate truncating length $\mathrm{d}$ of the patch can be calculated using equation 13 . The value of $\Delta S / S$ which is known as the truncation ratio is calculated first from equation 12. $Q_{0}$ is the unloaded quality factor of the patch and is calculated using cavity model. The value of $\mathrm{Q}_{0}$ always depends on the value of the dielectric constant and the substrate thickness $h$. Its value can be calculated from equation 11, where $\mathrm{c}$ is the velocity of light in space [14]. 


$$
\begin{aligned}
& Q o=\frac{c \sqrt{\varepsilon r}}{4 f r h} \\
& \frac{\Delta S}{S}=\frac{1}{2 Q o} \\
& d=L p \sqrt{\frac{\Delta S}{S}}
\end{aligned}
$$

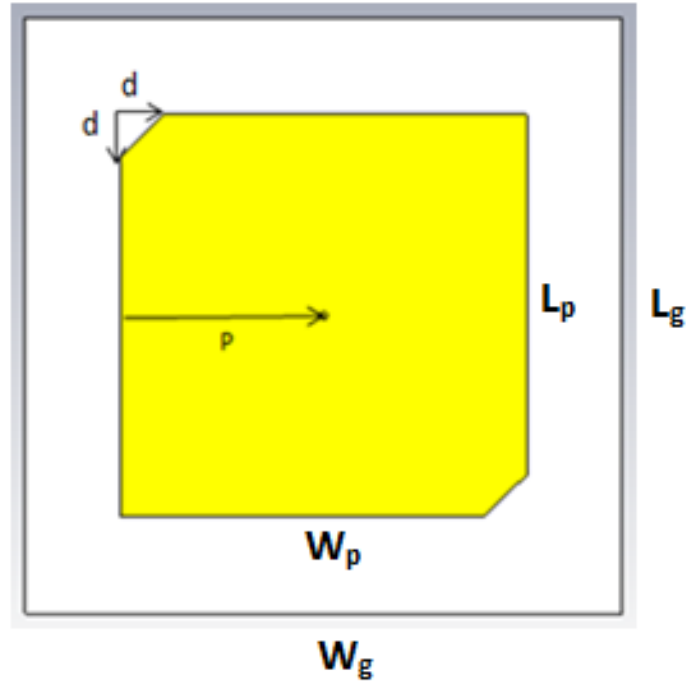

Fig.5 Truncated edges microstrip antenna

The Axial Ratio is measured in the broadband direction and is presented in Fig.6, after truncating the edges with $(\mathrm{d}=6.2 \mathrm{~mm})$. It shows that the microstrip truncated edges antenna is circularly polarized at the desired frequency where the Axial Ratio is smaller than $3 \mathrm{~dB}$.

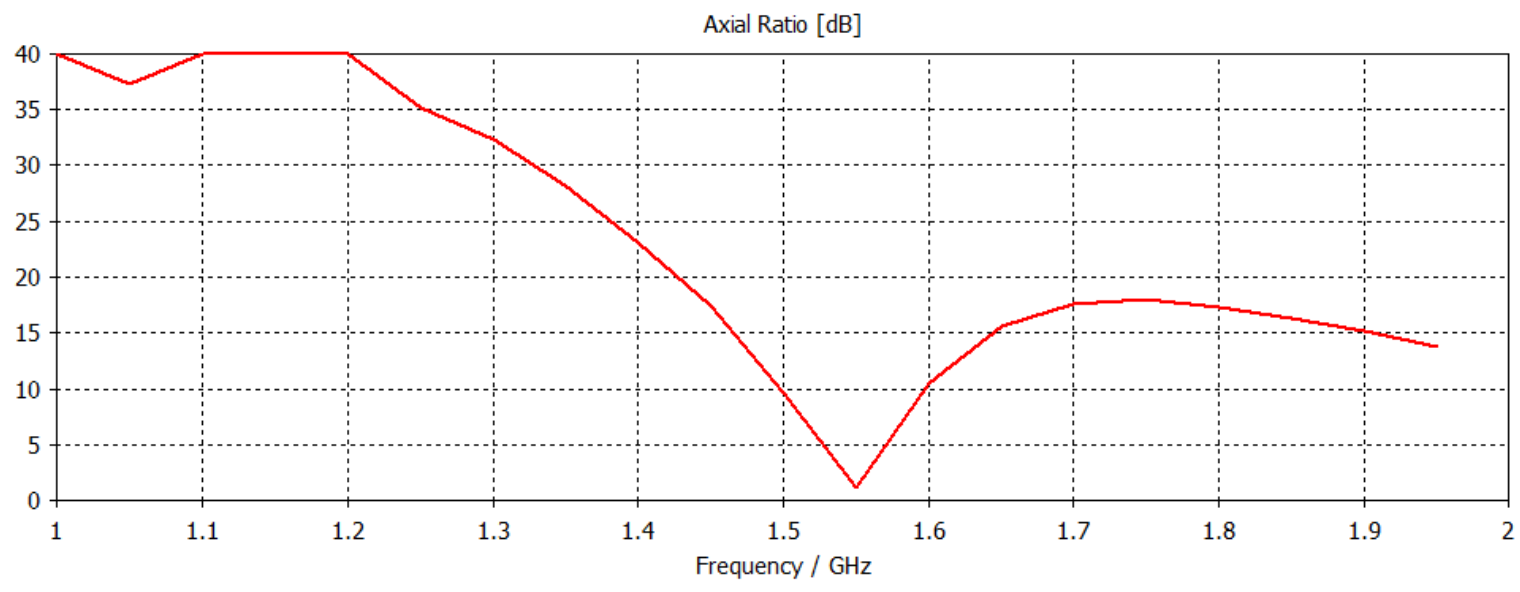

Fig.6 Axial Ratio for Truncated edges microstrip antenna antenna 


\section{Design of Transparent Microstrip Antenna}

\subsection{Design of Meshed Microstrip Antenna}

The same design for the solid microstrip is then sectioned into a meshed one with the same dimensions and the same transparent substrate. First we have to decide the number of vertical and horizontal lines $(\mathrm{M}, \mathrm{N})$ that will achieve the required transparency (PT $\geq 50 \%)$. The number of horizontal and vertical lines in this design at a fixed line width (q) is chosen to be equal $(\mathrm{M}=\mathrm{N})$, and is calculated using the following equation to get transparency better than $50 \%$. The line width $(\mathrm{q})$ is selected to be $(\mathrm{q}=1.2 \mathrm{~mm})$ for the patch and $\left(\mathrm{q}_{\mathrm{g}}=1.6 \mathrm{~mm}\right)$ for the ground plane.

$$
P T=1-\frac{M q L p+N q(W p-M q)}{\text { Apatch }} \times 100 \%
$$

This design resulted in resonance frequency less than the desired one (the resonance frequency is shifted to the left). It is observed that by increasing transparency of the meshed antenna the resonance frequency decreases. Fig.7 shows that The S11 parameter (return loss) of the antenna is not matched with the operating frequency, $\mathrm{f}_{\mathrm{r}}$ (radiated at $1.33 \mathrm{GHz}$ ). The antenna gain, $\mathrm{G}$ is equal to $5.51 \mathrm{dBi}$ and antenna, $\mathrm{e}_{\mathrm{o}}$ efficiency is equal to $86.02 \%$.

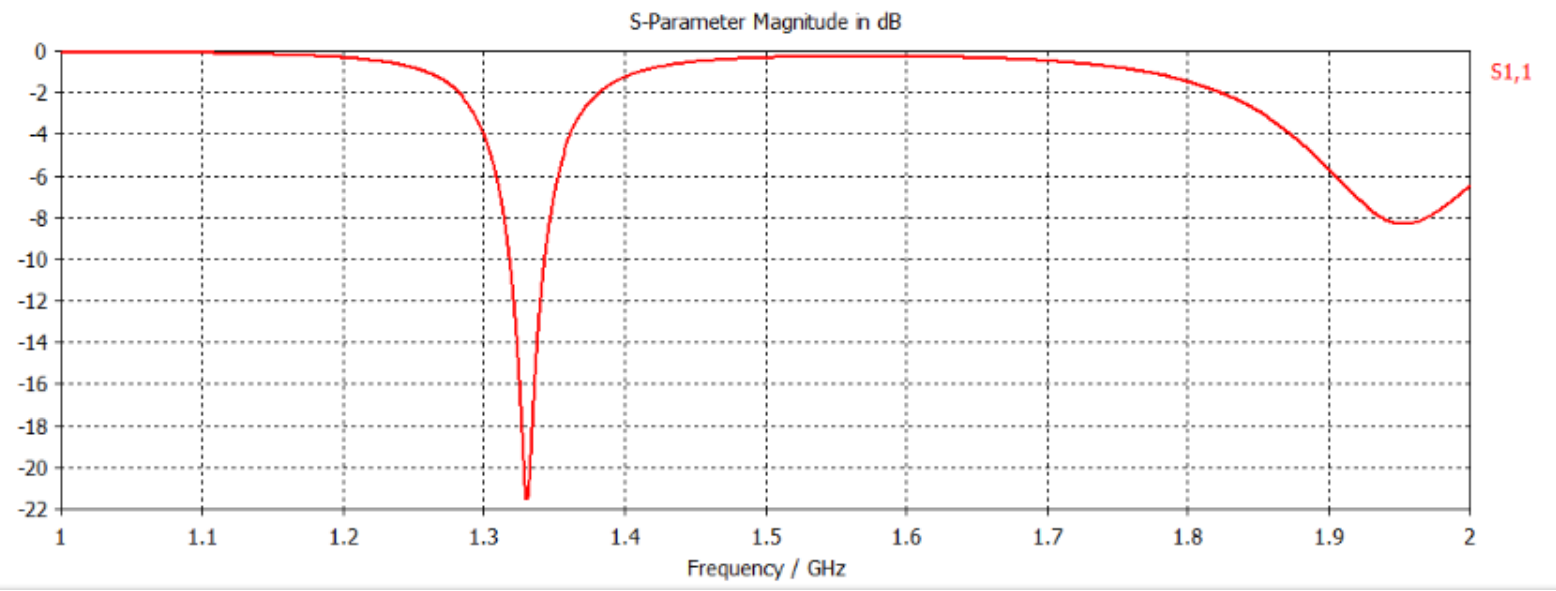

Fig.7 S11 (Return Loss) for the meshed microstrip antenna

\subsection{Optimized Meshed Microstrip Antenna at $1.575 \mathrm{GHz}$ results}

During optimization it was observed that as the size of the patch decreases for constant number of horizontal and vertical mesh lines the resonant frequency is shifted to the right. After several optimization trials the final design with the suitable dimensions is shown in Fig.8.

Table 4 Design patch dimensions for the meshed GPS microstrip antenna.

\begin{tabular}{|c|c|c|c|c|c|c|c|c|c|c|c|c|c|c|c|}
\hline $\mathrm{L}_{\mathrm{p}}$ & $\mathrm{W}_{\mathrm{p}}$ & $\mathrm{L}_{\mathrm{g}}$ & $\mathrm{W}_{\mathrm{g}}$ & $\mathrm{P}$ & $\mathrm{d}$ & $\mathrm{M}$ & $\mathrm{N}$ & $\mathrm{x}$ & $\mathrm{y}$ & $\mathrm{q}$ & $\mathrm{Ng}$ & $\mathrm{Mg}$ & $\mathrm{xg}$ & $\mathrm{Yg}$ & $\mathrm{qg}$ \\
\hline 45.3 & 45.9 & 85 & 85 & 13.1 & 4.9 & 10 & 10 & $\begin{array}{c}3.7 \\
\mathrm{~mm}\end{array}$ & $\begin{array}{c}3.766 \\
\mathrm{~mm}\end{array}$ & $\begin{array}{c}1.2 \\
\mathrm{~mm}\end{array}$ & $\begin{array}{c}10 \\
\mathrm{~mm}\end{array}$ & 10 & $\begin{array}{c}23 / 3 \\
\mathrm{~mm}\end{array}$ & $\begin{array}{c}23 / 3 \\
\mathrm{~mm}\end{array}$ & $\begin{array}{c}1.6 \\
\mathrm{~mm}\end{array}$ \\
$\mathrm{~mm}$
\end{tabular}




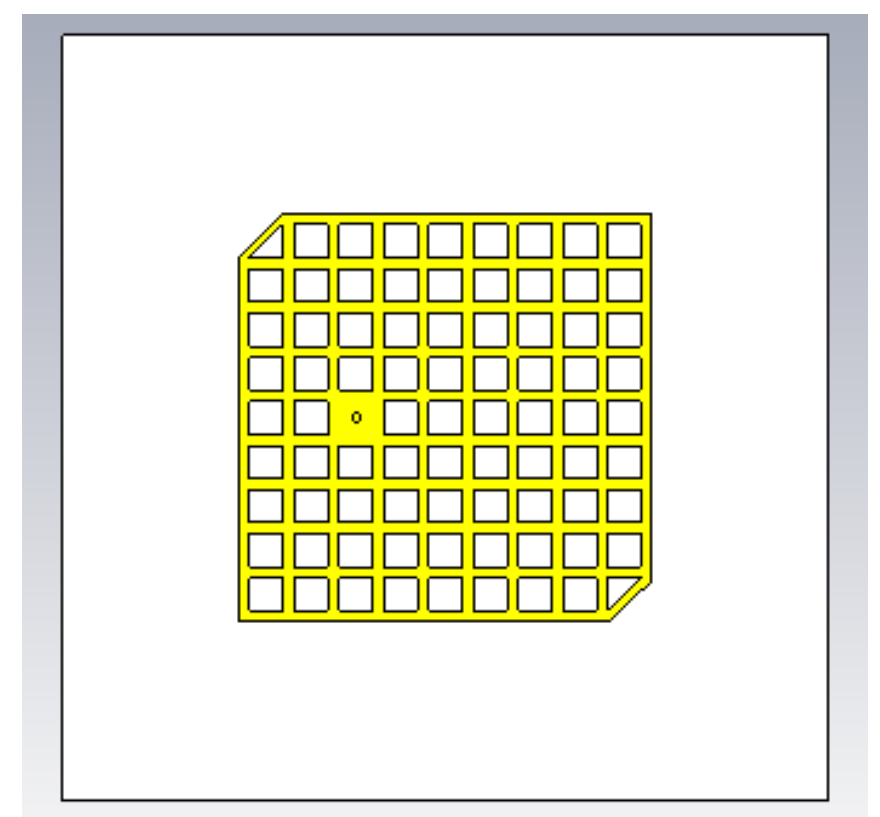

Fig. 8 a Meshed microstrip antenna front view $(\mathrm{M}=10, \mathrm{~N}=10)$

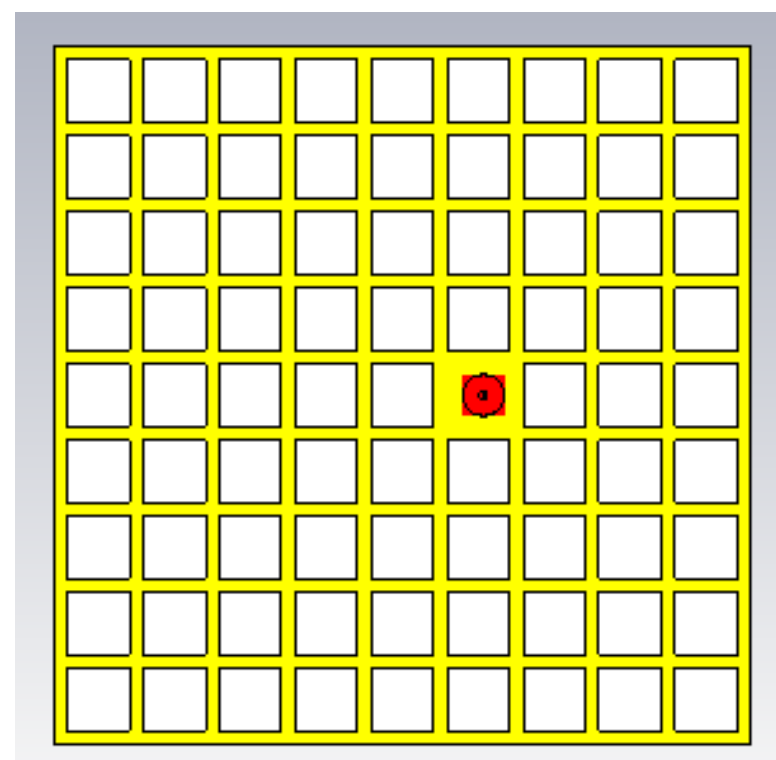

Fig.8b Meshed microstrip antenna back view $(M=10, N=10)$

The S11 parameter (return loss) shown in Fig.9, shows that the antenna is perfectly matched with the carrier frequency of the GPS $(1.575 \mathrm{GHz})$ with Bandwidth $64.7 \mathrm{MHz}(4.12 \%$ of operating frequency fr) and transparency of $60 \%$ which is suitable to allow sufficient solar energy to reach the solar cells installed beneath the antenna. 


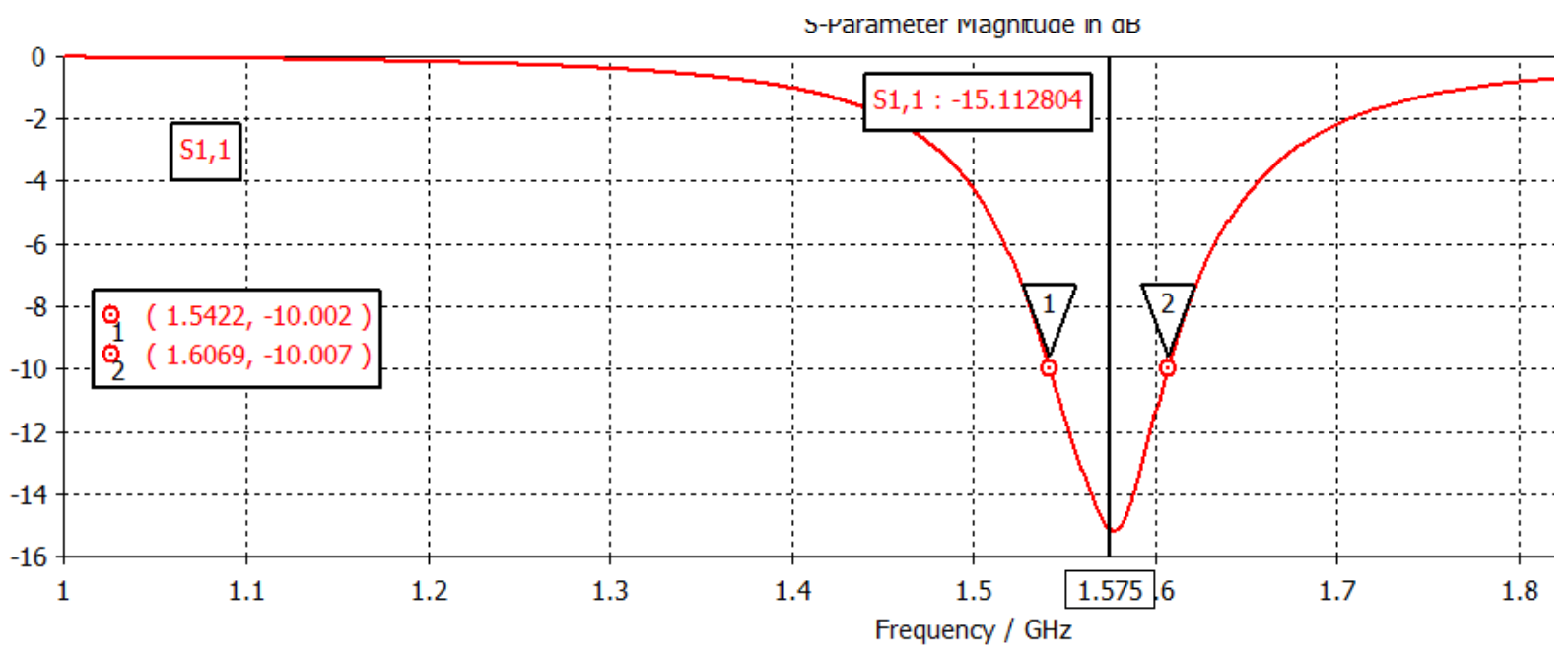

Fig.9 S11 (return loss) for the optimized meshed microstrip antenna

As shown in Fig.10 the antenna gain is equal to $6.052 \mathrm{dBi}$ antenna efficiency $96.45 \%$ which matches perfectly with the required specs.

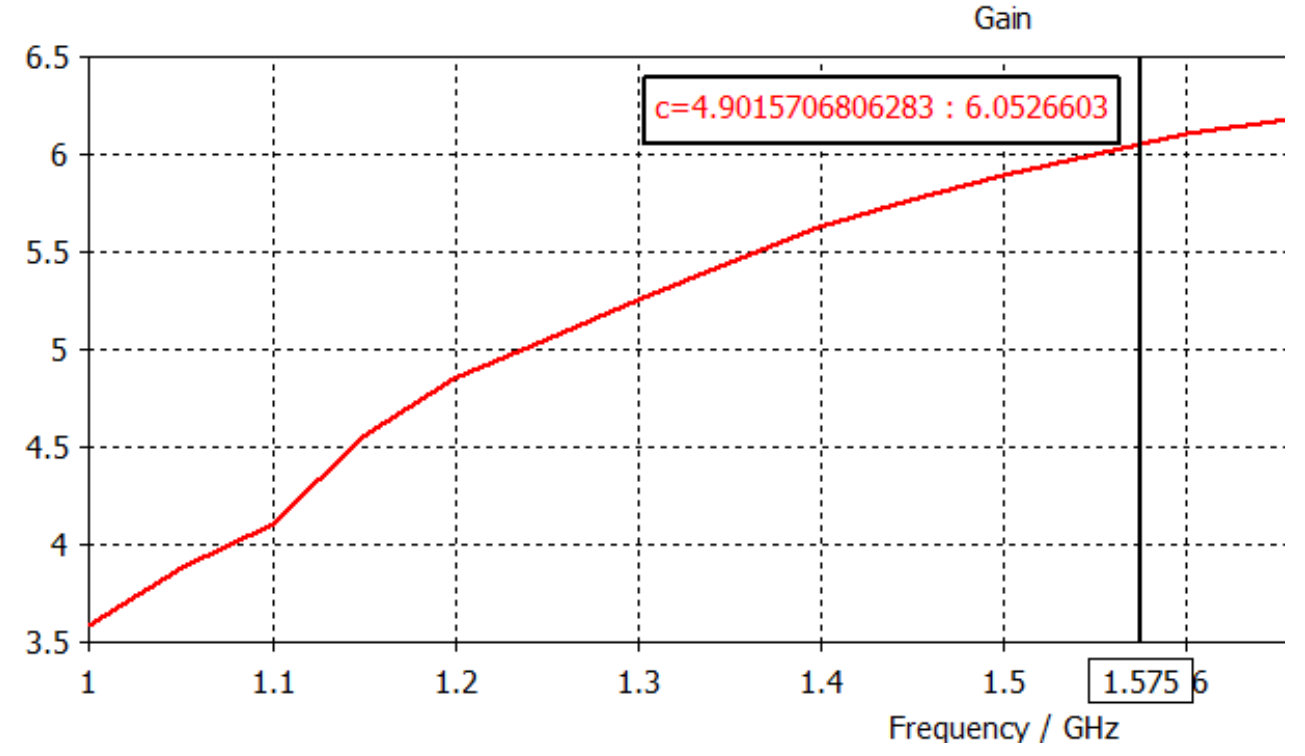

Fig.10 Gain of the optimized meshed microstrip antenna

The Axial Ratio is measured in the broadband direction and is presented in Fig.11. It shows that our GPS microstrip transparent antenna is circularly polarized at the desired frequency where the Axial Ratio is smaller than $3 \mathrm{~dB}$. 


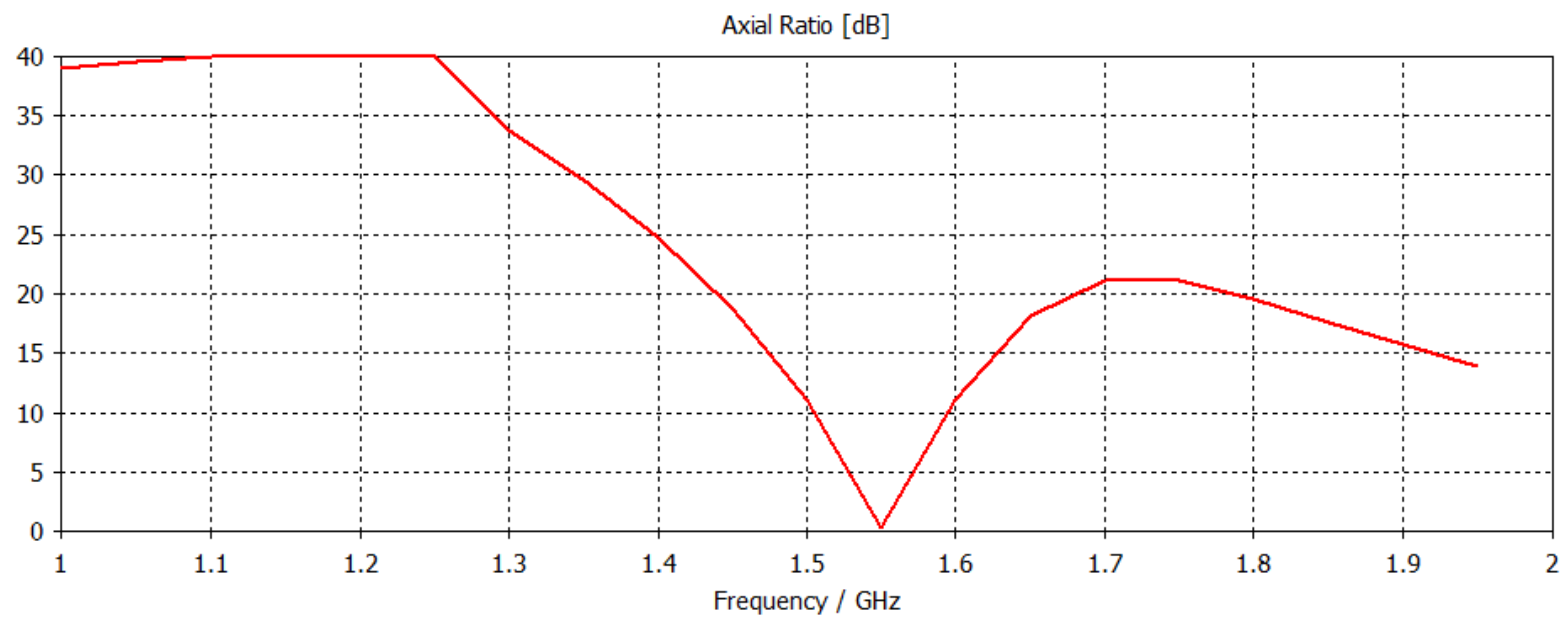

Fig.11 Axial Ratio of the optimized meshed microstrip antenna final design

Table 4 Summary of the final design results

\begin{tabular}{|l|l|c|}
\hline \multicolumn{1}{|c|}{ Antenna Parameter } & \multicolumn{1}{|c|}{ Value } & Unit \\
\hline Mesh Type & Rectangular & \\
\hline Patch Material & Copper & \\
\hline Substrate specs & $\begin{array}{l}\text { Quartz }(\varepsilon r=3.75, \text { tan } \delta= \\
0.0004)\end{array}$ & $\mathrm{mm}$ \\
\hline Substrate thickness, $\mathrm{h}$ & 3 & $\mathrm{GHz}$ \\
\hline Operating frequency, $\mathrm{f}_{\mathrm{r}}$ & 1.575 & $\mathrm{~mm}$ \\
\hline Width*Length $\left(\mathrm{W}_{\mathrm{p}} \mathrm{x} \mathrm{L}_{\mathrm{p}}\right)$ & $45.3 * 45.9$ & $\mathrm{~mm}$ \\
\hline $\mathrm{d}$ (removed edge side length) & 4.9 & $\mathrm{~mm}$ \\
\hline $\begin{array}{l}\text { P (Coaxial Probe feeder } \\
\text { Location) }\end{array}$ & 13.1 & $\mathrm{~dB}$ \\
\hline Return loss $(\mathrm{S} 11)$ & -15.7 & $\%$ \\
\hline Percentage of Transparency (PT) & 61 & $\mathrm{dBi}$ \\
\hline Gain [dB], G & 6.052 & $\mathrm{MHz}$ \\
\hline Bandwidth, BW & $64.7(4.12 \%$ of fr) & $\%$ \\
\hline Efficiency, $\mathrm{e}_{\mathrm{o}}$ & 96.45 & \\
\hline
\end{tabular}

\section{Conclusion}

In this paper, a rectangular transparent circularly polarized GPS microstrip antenna operating at frequency $\left(f_{r}=1.575 \mathrm{GHz}\right)$ for cubesat applications is designed and simulated. The antenna is simulated employing a finite element computational tool (CST). The transparency of the patch is achieved by gridding the patch into a meshed structure and by using a transparent substrate to get full transparency of the antenna. Circular polarization is achieved by cutting two isosceles triangles from the edges of the copper patch. The designed antenna meets the desired specs. The obtained parameters are antenna gain $(6.052 \mathrm{dBi})$, Bandwidth $(\mathrm{BW}=64.7$ $\mathrm{MHz}$ ) representing $4.12 \%$ of the operating frequency $\left(f_{r}\right)$, antenna efficiency $(e o=96.45 \%)$. Transparency (PT) of about $60 \%$ is achieved, which is considered sufficient to allow solar energy to reach the cells placed under the microstrip antenna. 


\section{References}

[1] Cal Poly CubeSat website: < http://cubesat.org >.

[2] R.Montano, N.Neuveu, S.Palacio, E.Martinez, D.R.Jackson and J.Chen, "Development of low profile antennas for cubesats", $28^{\text {th }}$ annual AIAA/USU conference on small satellites, 2013.

[3] S. Gao, et al., Underwood, M. Brenchley, M. Pointer, and M. N.Sweeting, "Antennas for Modern Small Satellites," Antennas and Propagation Magazine, vol. 51, pp. 40-56, 2009.

[4] Tursunjan Yasin, Reyhan Baktur, "Optically transparent multifunctional patch antennas integrated with solar cells for small satellites" Utah state university, 2015.

[5] Mahmoud, Mahmoud N., "Integrated Solar Panel Antennas for Cube Satellites" (2010). All Graduate Theses and Dissertations. Paper 742.

[6] Understanding GPS website : <http://www.montana.edu/gps/understd.html>.

[7] Muhammad Fadhli Bukhori, Norbahiah Misran1, Mohammad Tariqul Islam, Mawarni Mohamed Yunus1 and Mohammed Nazmus Shakib, "Design of Microstrip Antenna for GPS Application" IEEE, International Microwave and RF conference, 2008.

[8] Takafumi FUJIMOTO, Daisuke AYUKAWA Kouhei IWANAGA, Mitsuo TAGUCHI, "Dual-Band Circularly Polarized Microstrip Antenna for GPS Application" IEEE, 2008.

[9] B.T.P.Madhav, K.Praveen Kumar, J. Doondi Kumar, N. Venkatram Chowdary, M. Lakshmi Venkatesh, Chennu Durgarao, "Microstrip GPS Patch Ceramic Antenna", ISSN 2250-2459, Volume 2, Issue 4, April 2012.

[10] Shyh-Yeong Ke, "A Dual-band Microstrip Antenna for Precise GPS Applications".

[11] Clear Quartz Substrate website: <www.semiwafer.com/products/2quartz.htm>.

[12] J. Microw. Optoelectron. Electromagn. Appl. vol.11 no.1 São Caetano do Sul June 2012.

[13] Constantine A. Balanis, "Antenna Theory Analysis And Design", Third ed., New Jersey, John Wiley \& Sons, Inc., 2005.

[14] Khin Sandar Aung, Su SuYi Mon, "Comparison of Rectangular and Truncated Rectangular Patch Antenna for Ku-Band ", International Journal of Electronics and Computer Science Engineering, ISSN 2277-1956/V3-N2-159-166.

[15] M. J. Roo-Ons, S. V. Shynu,M. Ammann, S.McCormack, and B. Norton, "Transparent patch antenna on a-Si thin-film glass solar module," Electronics Letters, vol. 47, no. 2, pp. 85-86, 2011.

[16] Timothy W.turpin, "meshed patch antennas integrated on solar cell - a feasibility study and optimization" Master of Science thesis 2008.

[17] Dhanashri Jadhav Student, Dept. of SENSE, VIT University, Chennai Campus, Kelambakkam Road, Chennai, India, Vol. 4, Issue 5, May 2016.

[18] J. Bouwmeester and J. Guo, "Survey of worldwide pico- and nanosatellite missions, distributions and subsystem technology," Acta Astronaut., vol. 67, pp. 854-862, 2010.

[19] S. Gao, et al., Underwood, M. Brenchley, M. Pointer, and M. N.Sweeting, "Antennas for Modern Small Satellites," Antennas and Propagation Magazine, vol. 51, pp. 40-56, 2009.

[20] Guilin Sun, Badar Muneer and Qi Zhu “ A study of Microstrip Antenna made of ITO Films" Antennas and Propagation Society International Symposium (APSURSI), pp. 1867-1868 2014 IEEE .

[21] Mario Reyes-Ayala, Edgar Alejandro Andrade-Gonzalez, Jose Raul, Miranda-Tello, "Rectangular Microstrip Antenna for GPS receiver", pp.287-289. 